\title{
Morte na Família: \\ Um Estudo Exploratório Acerca da Comunicação à Criança
}

Death In The Family:

An Exploratory Study on Telling the Child

Muerte en la Familia:

Un Estudio Exploratorio Acerca de la Comunicación a Los Niños

Vanessa Rodrigues de Lima \& Maria Julia

Kovács

Universidade

de São Paulo

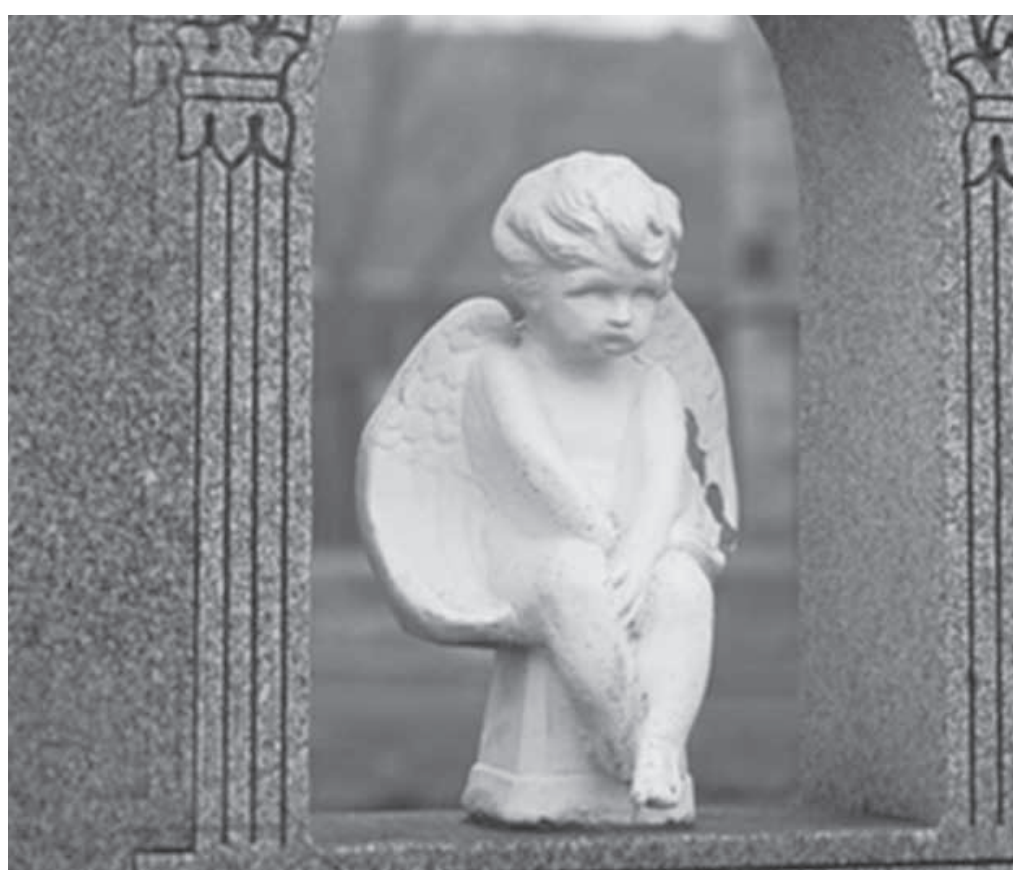


Resumo: A presente pesquisa investigou a comunicação da morte de parentes à criança, objetivando verificar sua adequação ao seu nível de desenvolvimento cognitivo e compreender o papel da família na elaboração do luto no que tange às informações e sentimentos compartilhados. Participaram responsáveis por crianças que sofreram a perda de um parente próximo quando tinham entre dois e oito anos de idade. Os dados foram coletados por meio de entrevistas abertas e analisados a partir da identificação de categorias recorrentes no discurso dos entrevistados. Os resultados apontam a importância de uma comunicação aberta e clara com a criança, além de adequada ao seu nível de compreensão; salientam os benefícios de se compartilharem sentimentos e demonstram a força do apoio social da família extensa no período pós-morte. Conclui-se que, apesar de difícil, a comunicação da morte de um parente próximo à criança é imprescindível e deve ser revestida de alguns cuidados básicos por parte do comunicador, que deve ser alguém com quem a criança tenha fortes laços de afetividade.

Palavras-chave: Morte. Criança. Luto. Comunicação. Atitudes frente a morte.

Abstract: The present work investigates how the communication of the death of a relative to a child occurs. The objectives were to verify the adequacy of such communication according to the cognitive development level of the child and to assess whether the family collaborates in the grieving process through the information shared. The participants in this study were those responsible for the children who had suffered the loss of a close relative between the ages of two and eight years old. The data were collected in open interviews and understood through the identification of recurrent categories in the speech of the people interviewed. The results pointed out the importance of an open and clear communication, adjusted to the child's level of understanding. They stress the benefits of sharing emotion, showing that the social support of the extensive family in the post-death period is very important. Finally, the communication of the death of a close relative to a child is essential, although difficult, and must be endeavored with the utmost care and sensitivity on the part of the communicator, who should be someone with strong affectivity bonds with the child.

Keywords: Death. Child. Grief. Communication. Death attitudes.

Resumen: La presente pesquisa investigó la comunicación de la muerte de parientes a los niños, objetivando verificar su adecuación al nivel de desarrollo cognitivo de la misma y comprender el papel de la familia en la elaboración del luto, en lo que atañe a las informaciones y sentimientos compartidos. Participaron responsables por niños que sufrieron la pérdida de un Pariente próximo cuando tenían entre dos y ocho años de edad. Los datos fueron recogidos por medio de entrevistas abiertas y analizados a partir de la identificación de categorías recurrentes en el discurso de los entrevistados. Los resultados apuntan a la importancia de una comunicación abierta y clara con el niño, además de adecuada a su nivel de comprensión; resaltan los beneficios de compartir sentimientos y demostrar la fuerza del apoyo social de la familia extensa en el período pos-mortuorio. Se concluye que, a pesar de difícil, la comunicación de la muerte de un pariente próximo al niño es imprescindible y debe ser revestida de algunos cuidados básicos por parte del comunicador, que debe ser alguien con quien el niño tenga fuertes lazos de afectividad.

Palabras clave: Muerte. Niño. Luto. Comunicación. Actitud frente la muerte.

O século XXI abriga um paradoxo: com relação à morte, o interdito e o escancarado convivem lado a lado. Ao mesmo tempo em que as crianças são poupadas de ir a velórios e enterros, assistem por horas a fio programas de televisão violentos, nos quais a morte é tratada como evento banal (Kovács, 2003).

\section{Anteriormente à contradição patente nos} tempos atuais, o homem já lidou de outras maneiras com a temática da morte. Sobre as cerimônias de morte, nos diz Ariès (1977):

Levavam-se as crianças - não há representação de um quarto de moribundo até o século XVIII sem algumas crianças. E quando se pensa nos cuidados tomados hoje em dia para afastar as crianças das coisas da morte! (p. 21)

A sociedade contemporânea supõe que a criança não compreenda a morte, e encara tudo que lhe é associado como prejudicial a ela, mantendo um silêncio amedrontador, desconversando ou protegendo-se com metáforas quando se trata de conversar com os pequenos sobre esse tema.

Torres (1999) ressalta que silenciar sobre a morte pode acarretar perturbações no desenvolvimento da criança que se tornam evidentes, sobretudo quando ela passa por certas experiências, como a perda e o luto. 
Alguns fatores que podem influenciar no processo de luto e nas reações da criança são: sua idade, etapa de desenvolvimento, estabilidade psicológica e emocional e a intensidade dos laços afetivos, além do tipo de comunicação que se desenvolve dentro da família.

\section{Fases do desenvolvimento e o conceito de morte na criança}

Torres (1978) investigou a relação entre o desenvolvimento do conceito de morte e o nível de desenvolvimento cognitivo a partir de uma perspectiva piagetiana, em uma amostra de 183 crianças entre quatro e treze anos de idade. A autora identificou três níveis de desenvolvimento do conceito de morte descritivos do pensamento da criança nos diferentes períodos de desenvolvimento cognitivo:

Nível 1 (característico de crianças do subperíodo pré-operacional): não estabelecem claramente a oposição entre animados e inanimados, admitem vida na morte e não compreendem a morte como um processo definitivo e irreversível.

Nível 2 (característico de crianças do subperíodo de operações concretas): progridem em sua capacidade para distinguir entre animados e inanimados, já fazem oposição entre a vida e a morte, não mais atribuem vida e funcionamento biológico ao morto, definem a morte a partir de aspectos perceptivos, não sendo capazes de estabelecer generalizações ou dar explicações biologicamente essenciais, já compreendem a morte como uma condição definitiva e permanente.

Esse subperíodo do desenvolvimento é apontado como um momento crucial, uma vez que nele surgem as mais importantes estruturas cognitivas. Com a aquisição da reciprocidade e com o desenvolvimento da noção de constância do eu e do objeto, a aceitação de vida na morte e a crença na temporalidade e reversibilidade da morte desaparecem.

- Nível 3 (característico do subperíodo operatório formal do desenvolvimento): as crianças estabelecem claramente a ampla distinção entre animados e inanimados, reconhecem a morte como extensiva a todos os seres animados e dão explicações biologicamente essenciais.

\section{Luto infantil}

Ao discorrer sobre a importância de se estudar o luto na atualidade, Franco (2010) ressalta que, até as duas últimas décadas do século $\mathrm{XX}$, os estudos sobre o luto preconizavam a necessidade de desligamento emocional da pessoa falecida. Também por muito tempo, o luto foi associado à doença mental, em uma clara proximidade do luto com a depressão (Freud, 1917/1974; Bowlby, 1982).

Outro modelo bastante utilizado na compreensão do processo de luto foi o desenvolvido por John Bowlby na década de 40. Para Bowlby (1982), bebês e crianças pequenas que perderam uma pessoa amada sentem pesar e passam por períodos de luto tal como o adulto. O autor identifica quatro etapas principais no processo de luto: 1 . fase de entorpecimento; 2 . fase de protesto e busca da figura perdida; 3 . fase de desorganização e desespero e 4 . fase de reorganização.

Atualmente, novas visões sobre o luto se apresentam, e teorias que consideram pessoas enlutadas como doentes têm sido revistas. Já não se concebe mais, como fator de compreensão do processo de luto, que as pessoas passem por várias fases em sequência. Segundo Franco (2010), esse modelo de fases ainda se respalda na ideia de que existiriam 
modos bons e maus de viver o luto, posição cada vez mais questionada, sobretudo face ao conceito de resiliência, apontado como componente importante para a compreensão de diferenças individuais.

A tendência contemporânea frente ao período de luto dá ênfase à capacidade de reaprender o mundo, construindo e encontrando significados para essa fase. $\mathrm{O}$ estudo do luto a partir dessa perspectiva de construção de significado (Neimeyer, 2001) sugere revisões na identidade, nas relações sociais, nas relações com o morto e no sistema de crenças. Mais do que um modelo, buscase considerar os valores e crenças de uma dada cultura que matiza os processos de luto de cada pessoa, como apontam Parkes, Laugani e Young (1997).

Uma outra possibilidade atual na compreensão do luto envolve a perspectiva dos vínculos contínuos, como destacaram Klass, Silverman e Nickman (1996). Essa se opõe às teorias que determinam o fim do processo do luto com o desligamento objetal, propondo a manutenção dos vínculos de maneira diferente da que existia antes da morte, uma vez que a tentativa de manter os vínculos como se a pessoa não estivesse morta pode impedir a adaptação à perda, não permitindo que o luto avance no seu processo.

Em relação ao luto infantil, algumas predições gerais sobre as reações da criança podem ser feitas com base em padrões de desenvolvimento cognitivo e emocional apresentados nos diferentes estágios da infância. Essas considerações gerais dão a qualidade e a natureza do suporte que poderá ser oferecido à criança enlutada (Bromberg, 2000).

De acordo com Torres (1999), as reações mais frequentes da criança frente à morte são: manifestações somáticas, reações hostis em relação ao morto por se sentir abandonada por este (sobretudo se foi um dos progenitores que morreu), reações hostis aos outros, idealização das qualidades do ente perdido, identificação com ele, pânico decorrente da vivência do desamparo e culpa.

Quanto à sintomatologia, Weller e Weller (1992), ao realizarem estudo com crianças recentemente enlutadas, constataram que estas apresentaram sintomas depressivos como disforia, perda de interesse, tristeza, culpa, desempenho escolar diminuído, retardo psicomotor e ideação mórbida mais frequentemente que crianças não enlutadas.

Harris (1991) verificou que crianças manifestam sintomas físicos e psíquicos, apresentando problemas na escola quando vivem mortes de pessoas próximas. Crianças que viveram perdas podem apresentar problemas sociais, baixa autoestima e ansiedade, o que ressalta a necessidade de os professores saberem desses fatos para compreender e acolher seus alunos.

Cumpre ressaltar que, em se tratando de crianças enlutadas, os processos familiares constituem determinantes cruciais da adaptação saudável ou disfuncional à perda. A comunicação intrafamiliar é vital no curso do processo de luto infantil, uma vez que a elaboração do luto na criança é fortemente influenciada pelo quê e como os responsáveis conversam com ela, pela maneira como lidam com suas expressões emocionais e, no caso da morte de um dos pais, pelo modo como o genitor sobrevivente reage e espera que a criança reaja.

Uma informação clara e uma comunicação aberta sobre os fatos e circunstâncias da morte facilitam o reconhecimento da perda. Embora os indivíduos, as famílias e as culturas variem no grau em que a expressão aberta dos sentimentos é valorizada, evidências 
Segundo Torres (1999), a falta de informação sobre o que realmente aconteceu contribui para que a criança dê asas à imaginação, formando uma visão distorcida da morte de seu ente querido e alimentando medos e culpa. demonstram que a comunicação clara e direta promove a adaptação familiar e fortalece a família como rede de apoio para seus membros (Walsh \& McGoldrick, 1998).

\section{Comunicando uma morte na família}

Falar com a criança sobre a morte não é tarefa fácil. Além da necessidade de protegê-la, falar sobre a morte implica, para o adulto, defrontar-se com sua própria finitude, medos e ansiedades (Kastenbaum \& Aisenberg, 1983).

Especificamente em situações de crise, as crianças revelam necessidade de compartilhar seus medos, angústias, fantasias e sentimentos. Nessas horas, o cuidador deverá estar preparado para transmitir e propiciar a esses pequenos seres conforto, segurança e força para continuar (Lione, 2005). Franco (2002), Kovács (2003), Stroebe e Schut (2001) apontam a importância de que o adulto, ao atuar como facilitador no processo de luto da criança, compartilhe a dor pela perda da pessoa querida e favoreça a comunicação, buscando amenizar o sofrimento.

Nos casos em que a comunicação é bloqueada, o indizível tem mais chances de se manifestar por meio de sintomas disfuncionais ou de comportamentos destrutivos. Segundo Torres (1999), a falta de informação sobre o que realmente aconteceu contribui para que a criança dê asas à imaginação, formando uma visão distorcida da morte de seu ente querido e alimentando medos e culpa.

Todavia, o adulto deve estar ciente de que a negação da criança frente a alguns aspectos da morte pode ser algo necessário. A negação, como ressalta Anthony (1972), é uma etapa entre a recusa e a aceitação da realidade, uma forma de promover a construção de uma relação pragmática entre o indivíduo e o meio.
É grande o desespero dos adultos diante das perguntas da criança sobre a morte. Contudo, as próprias palavras da criança permitem que se estabeleça um diálogo e que se formulem questões junto a ela. Deixar a criança dar o tom e estabelecer o ritmo da conversa parece a maneira mais apropriada de se abordar esse tema. Não esquecendo de respeitar seu nível de desenvolvimento, utilizar uma linguagem acessível e servir-se, sempre que necessário, de elementos facilitadores, como, por exemplo, a literatura infantil, os desenhos animados e os filmes.

É importante mencionar que aquele que comunica também está de luto e, portanto, sofre e necessita de apoio tanto quanto a criança. Em muitos momentos, não se sabe como agir, não se tem as respostas ou não se encontram as palavras adequadas ou suficientes; nessas horas, um afago, um abraço apertado, a troca de carinhos pode fazer toda diferença.

\section{Objetivos}

\section{Geral}

- Verificar como se processa a comunicação da morte de um familiar à criança.

\section{Específicos}

- Verificar se essa comunicação foi a mais adequada ao nível de desenvolvimento cognitivo da criança;

- Verificar se a família facilitou a expressão de sentimentos pela criança;

- Identificar os motivos que levaram a família a buscar apoio profissional para a criança enlutada e que tipo de apoio foi o mais solicitado.

\section{Método}

\section{Participantes}

Participaram da pesquisa adultos que comunicaram a morte de um parente 
próximo (mãe, pai ou irmão) a uma criança com idade entre dois e oito anos à época da perda. Os participantes foram contatados após divulgação da pesquisa boca-a-boca e pela internet. Todos participaram de forma voluntária, tiveram sigilo garantido e assinaram o Termo de Consentimento Livre e Esclarecido.

As participantes eram mulheres (3 mães e 1 avó) entre 40 e 58 anos de idade, sendo duas profissionais de saúde, uma advogada e uma funcionária pública. Duas delas se declararam sem religião, uma disse que era católica não praticante, e outra, que havia sido criada no catolicismo, mas que seguia o kardecismo.

\section{Coleta dos dados}

Os dados foram coletados por meio de entrevistas abertas. Iniciou-se a entrevista com a seguinte questão: Fale sobre a morte de seu parente (esposo (a), filho (a)) focando, principalmente, o modo como essa notícia foi transmitida à (s) criança (s).

Os entrevistados responderam livremente à questão, que contava com alguns pontos norteadores:

- quem comunicou à criança e que tipo de vínculo tinha com ela;

se foram utilizadas metáforas;

- se houve omissão de informações, quais e por quê;

- se havia estímulo para as crianças se expressarem e questionarem sobre o ocorrido;

- nos casos de morte anunciada, se a criança sabia e se foi preparada;

- como foi o comportamento imediato da criança e nos meses subsequentes à perda;

- quem a acompanhou no desenrolar do processo de luto e como foi o processo de luto desse acompanhante.

As entrevistas foram realizadas individualmente com o responsável pela criança que sofreu a perda; posteriormente, foram transcritas e analisadas.

\section{Compreensão dos dados}

A compreensão dos dados se baseou na análise temática, tal como proposta por Minayo (2000): Fazer uma análise temática consiste em descobrir os núcleos de sentido que compõem uma comunicação cuja presença ou frequência signifique alguma coisa para o objetivo analítico visado (p. 209).

Após a transcrição, procedeu-se ao levantamento dos principais temas e categorias descritivas a partir da leitura e releitura das entrevistas. Para tanto, levaram-se em conta as características do discurso e a repetição de falas no texto. Inicialmente, o levantamento se deu a partir da fala de cada participante; posteriormente, os aspectos comuns a todos foram destacados.

\section{Resultados e discussão}

Foram observadas várias configurações familiares, o que implica reorganizações diferentes da vida após a morte. A Tabela 1, abaixo, apresenta os tipos de perda abordados: 
Tabela 1. Configuração das perdas

\begin{tabular}{|c|c|c|c|c|}
\hline & Entrevista 1 & Entrevista 2 & Entrevista 3 & Entrevista 4 \\
\hline Ente perdido & Pai (marido) ${ }^{1}$ & Mãe (filha) & Pai (marido) & Irmã (filha) \\
\hline Tipo de morte & $\begin{array}{l}\text { Anunciada / } \\
\text { doença / } \\
\text { desfecho rápido }\end{array}$ & $\begin{array}{l}\text { Repentina/violenta } \\
\text { homicídio }\end{array}$ & $\begin{array}{l}\text { Repentina/violenta } \\
\text { homicídio }\end{array}$ & Repentina/acidente \\
\hline $\begin{array}{l}\text { Fase do ciclo } \\
\text { de vida } \\
\text { familiar }\end{array}$ & $\begin{array}{l}\text { Casal jovem com } \\
\text { filhos pequenos }\end{array}$ & $\begin{array}{l}\text { Filha adulta jovem, } \\
\text { recém-saída de casa }\end{array}$ & $\begin{array}{l}\text { Casal jovem com } \\
\text { filho pequeno }\end{array}$ & $\begin{array}{l}\text { Casal jovem com } \\
\text { doisfilhos pequenos }\end{array}$ \\
\hline $\begin{array}{l}\text { Outros } \\
\text { complicadores } \\
\text { associados }\end{array}$ & Viuvez precoce & $\begin{array}{l}\text { Ambiguidade em } \\
\text { torno da perda }\end{array}$ & Viuvez precoce & $\begin{array}{l}\text { Inversão da ordem } \\
\text { natural }\end{array}$ \\
\hline
\end{tabular}

A entrevista 1 foi concedida por Maria Amélia, mãe de Bruno e Ricardo, 18 e 24 anos, que perderam o pai em consequência de um câncer quando tinham dois anos e meio e oito anos, respectivamente. Maria Amélia tem 58 anos, é psicóloga e não tem religião.

A entrevista 2 foi realizada com Maria Eduarda, avó materna de Pablo, oito anos, que perdeu a mãe assassinada pelo pai, aos dois anos de idade. Maria Eduarda tem 50 anos, é funcionária pública aposentada, católica de criação e praticante do kardecismo. Atualmente, é a responsável por Pablo.

A entrevista 3 foi dada por Maria João, mãe de Tiago, dez anos de idade, que perdeu o pai aos oito anos em uma tentativa de assalto seguida de morte. Maria João tem 40 anos, é advogada e católica não praticante.

Finalmente, a entrevista 4 foi concedida por Maria Rita, mãe de Fernando, sete anos, que perdeu a irmã aos quatro, em consequência de um acidente. Maria Rita tem 42 anos, é profissional de saúde e declarou-se sem religião.

A Tabela 2 facilita a visualização de alguns temas recorrentes que surgiram nas entrevistas.

1 A descrição fora dos parênteses informa o parentesco do falecido com a criança, e, entre parênteses, tem-se o parentesco entre o ente perdido e o entrevistado. 
Tabela 2. Temas recorrentes

\begin{tabular}{|c|c|c|c|c|}
\hline & Entrevista 1 & Entrevista 2 & Entrevista 3 & Entrevista 4 \\
\hline $\begin{array}{l}\text { Quem } \\
\text { comunicou } \\
\text { quando } \\
\text { comunicou }\end{array}$ & $\begin{array}{l}\text { Mãe } \\
\text { No mesmo dia } \\
\text { para a criança } \\
\text { mais velha; no } \\
\text { dia seguinte, } \\
\text { para a mais } \\
\text { nova }\end{array}$ & $\begin{array}{l}\text { Avó } \\
\text { Um ano depois }\end{array}$ & $\begin{array}{l}\text { Mãe } \\
\text { No mesmo dia }\end{array}$ & $\begin{array}{l}\text { Mãe e pai } \\
\text { No dia seguinte }\end{array}$ \\
\hline $\begin{array}{l}\text { Tipo de } \\
\text { comunicação }\end{array}$ & $\begin{array}{l}\text { Realista; } \\
\text { preparação das } \\
\text { crianças; falavam } \\
\text { bastante sobre } \\
\text { o pai }\end{array}$ & $\begin{array}{l}\text { Tardia e } \\
\text { metafórica; } \\
\text { silenciaram } \\
\text { em torno da } \\
\text { morte }\end{array}$ & $\begin{array}{l}\text { Dosada e realista; } \\
\text { falavam sobre o } \\
\text { pai de uma forma } \\
\text { contida }\end{array}$ & $\begin{array}{l}\text { Realista; falavam } \\
\text { com muita } \\
\text { frequência e } \\
\text { abertamente } \\
\text { sobre a irmã }\end{array}$ \\
\hline $\begin{array}{l}\text { Uso de } \\
\text { metáforas }\end{array}$ & Da estrela & Religiosa & Não houve & Do céu e da estrela \\
\hline $\begin{array}{l}\text { Reações } \\
\text { imediatas } \\
\text { Reações a } \\
\text { longo prazo }\end{array}$ & $\begin{array}{l}\text { Choro; } \\
\text { abraçaram-se } \\
\text { Comportamento } \\
\text { desafiante; não } \\
\text { sabe ouvir um } \\
\text { não }\end{array}$ & $\begin{array}{l}\text { Não se lembrava } \\
\text { da mãe } \\
\text { Agressividade, } \\
\text { gagueira, } \\
\text { problemas na } \\
\text { escrita }\end{array}$ & $\begin{array}{l}\text { Chorou, berrou; } \\
\text { abraçaram-se } \\
\text { Cuidado demasiado } \\
\text { com a mãe; medo; } \\
\text { amadurecido }\end{array}$ & $\begin{array}{l}\text { Quer comprar } \\
\text { tudo, não suporta } \\
\text { ouvir um não; } \\
\text { agressividade; } \\
\text { amadurecido }\end{array}$ \\
\hline UTI & $\begin{array}{l}\text { As crianças não } \\
\text { foram à UTI }\end{array}$ & & $\begin{array}{l}\text { A criança não } \\
\text { foi à UTI }\end{array}$ & \\
\hline $\begin{array}{l}\text { Participação } \\
\text { nos rituais } \\
\text { funerários }\end{array}$ & $\begin{array}{l}\text { As crianças } \\
\text { não foram }\end{array}$ & Não foi & Não foi & A criança não foi \\
\hline Fantasias & $\begin{array}{l}\text { Culpa e espera } \\
\text { pelo pai morto }\end{array}$ & Culpa & Culpa & $\begin{array}{l}\text { Culpa e tentativa } \\
\text { de trazer a irmã } \\
\text { de volta }\end{array}$ \\
\hline Lembranças & $\begin{array}{l}\text { A criança } \\
\text { mais nova } \\
\text { tem poucas } \\
\text { lembranças do } \\
\text { pai }\end{array}$ & $\begin{array}{l}\text { A criança } \\
\text { apagou a mãe } \\
\text { da memória }\end{array}$ & $\begin{array}{l}\text { Lembra-se } \\
\text { detalhadamente } \\
\text { do pai e fala dele } \\
\text { com frequência }\end{array}$ & $\begin{array}{l}\text { Tem muitas } \\
\text { lembranças, } \\
\text { recorda de } \\
\text { detalhes de } \\
\text { quando ainda era } \\
\text { bem pequeno }\end{array}$ \\
\hline $\begin{array}{l}\text { Identificação } \\
\text { com o falecido }\end{array}$ & $\begin{array}{l}\text { Crianças } \\
\text { cresceram tendo } \\
\text { o pai como } \\
\text { referência }\end{array}$ & $\overline{(12}$ & $\begin{array}{l}\text { É igual ao pai; } \\
\text { reproduziu seus } \\
\text { traços mais } \\
\text { característicos }\end{array}$ & - \\
\hline $\begin{array}{l}\text { Suporte } \\
\text { familiar }\end{array}$ & $\begin{array}{l}\text { A família } \\
\text { extensa deu } \\
\text { suporte }\end{array}$ & $\begin{array}{l}\text { Suporte apenas } \\
\text { dos parentes bem } \\
\text { próximos }\end{array}$ & $\begin{array}{l}\text { Família grande, } \\
\text { sempre presente } \\
\text { prestando apoio }\end{array}$ & $\begin{array}{l}\text { A família extensa } \\
\text { deu suporte }\end{array}$ \\
\hline $\begin{array}{l}\text { Cuidado } \\
\text { mútuo }\end{array}$ & $\begin{array}{l}\text { As crianças } \\
\text { autorizavam } \\
\text { e amparavam } \\
\text { o sofrimento } \\
\text { da mãe; a } \\
\text { importância de } \\
\text { ter as crianças } \\
\text { para cuidar }\end{array}$ & $\begin{array}{l}\text { A criança consola } \\
\text { a avó quando a vê } \\
\text { chorando; } \\
\text { a importância de ter } \\
\text { o neto para cuidar }\end{array}$ & $\begin{array}{l}\text { O filho cuida da } \\
\text { mãe, preocupa- } \\
\text { se com seu bem } \\
\text { estar e em não } \\
\text { levantar sofrimento } \\
\text { adicional }\end{array}$ & - \\
\hline
\end{tabular}


Continuação tabela 2

\begin{tabular}{|c|c|c|c|c|}
\hline & Entrevista 1 & Entrevista 2 & Entrevista 3 & Entrevista 4 \\
\hline & Mãe & Avó & Mãe & Mãe e pai \\
\hline $\begin{array}{l}\text { O luto dos } \\
\text { adultos }\end{array}$ & $\begin{array}{l}\text { De dia } \\
\text { amparava } \\
\text { os filhos, à } \\
\text { noite, chorava } \\
\text { escondida }\end{array}$ & $\begin{array}{l}\text { Não chorou; } \\
\text { quando acharam } \\
\text { o corpo da sua } \\
\text { filha desabou }\end{array}$ & $\begin{array}{l}\text { Tentava não } \\
\text { chorar na frente } \\
\text { do filho }\end{array}$ & $\begin{array}{l}\text { Compartilharam } \\
\text { o luto, a família } \\
\text { chorava junta }\end{array}$ \\
\hline Terapia & $\begin{array}{l}\text { A mãe busca } \\
\text { terapia }\end{array}$ & - & $\begin{array}{l}\text { A mãe busca } \\
\text { terapia }\end{array}$ & $\begin{array}{l}\text { A criança já fazia } \\
\text { terapia antes } \\
\text { do ocorrido e } \\
\text { continuou }\end{array}$ \\
\hline
\end{tabular}

A transmissão da notícia da morte ocorreu em todos os casos, apesar da variação no tempo decorrido entre a morte e sua comunicação à criança. As crianças mais velhas foram postas a par de imediato; as mais novas não receberam a notícia no mesmo dia. Duas delas tiveram conhecimento do ocorrido no dia seguinte, e a terceira só recebeu a notícia de que a mãe havia falecido um ano depois.

Inicialmente por causa da ambiguidade em torno da perda, Maria Eduarda escondeu de Pablo o que havia acontecido com a mãe: "Eu falei: 'eu não vou falar para o meu neto que a mãe dele é desaparecida'. Até então eu não tinha certeza se ela estava morta ou não. (...) Resultado, escondi tudo" (Maria Eduarda).

Esconder sentimentos, principalmente tristeza, raiva e medo, pode estar pautado na crença de que é importante proteger a criança da dor e do sofrimento. Essa atitude traduz uma forma de conspiração do silêncio, muito comum atualmente, em tempos de morte interdita (Kovács, 2003). Entretanto, as crianças observam seu entorno tentando adivinhar o que está acontecendo, como se pode observar nesta fala de Maria Eduarda, avó do pequeno Pablo:

Quando eu fui na casa de uma amiga dela (da filha falecida),... Ela ia muito para a casa dessa amiga e levava o Pablo. Aí, quando eu cheguei com o Pablo lá..., a primeira coisa, quando ele estava subindo as escadas, que não tinha elevador, ele subiu correndo, correndo, tipo assim, na esperança de encontrar a mãe lá. Quando ele chegou lá, ele entrou correndo no quarto onde elas dormiam, não viu a mãe e voltou. Aquilo lá me deu uma dó. Quer dizer, ele estava ainda querendo procurar a mãe, mas sem conseguir falar. Aí eu falei para ele assim... Ele falava algumas coisas só. Eu falei: 'Pablo, a mamãe não está', eu falei para ele; aí ele se abraçou em mim, pronto (Maria Eduarda).

Nos dois casos de perda do pai, foram as mães que deram a notícia; no caso de perda da mãe, quem comunicou foi a avó materna; a morte da irmã foi comunicada por pai e mãe juntos.

Nas entrevistas 1, 3 e 4, a notícia foi passada de maneira bastante real e concreta. Aqueles que tiveram que comunicar a morte às crianças mais novas preocuparam-se em usar palavras que representassem efetivamente o ocorrido, dando ênfase à irreversibilidade da morte, como pode ser visto na preocupação demonstrada por Maria Amélia, que é psicóloga, em adequar a linguagem utilizada ao nível de desenvolvimento da criança: 
Tinha uma preocupação de escolher uma boa palavra que representasse a coisa efetiva e não assim que nem um brinquedo que quebrou ou estragou. Eu tinha preocupação com essas palavras. Então eu achei que esta frase era uma frase limpa: 'Papai morreu, papai não volta mais'. Eu dizia o que aconteceu e a consequência (Maria Amélia).

Entretanto, a metáfora foi uma ferramenta utilizada por aqueles que tiveram que comunicar às crianças pequenas. As metáforas escolhidas foram: "Foi para o céu" e "Virou estrela". Apesar de crianças do nível préoperatório ainda não terem o pensamento abstrato desenvolvido, o que indica uma dificuldade para compreender metáforas, estas foram utilizadas na tentativa de atenuar o sofrimento que a perda pode provocar, como se pode ver pela fala dessa mãe:

(...) Ele perguntava para todas as pessoas, todas que apareciam na frente dele, ele dizia: 'Cadê o meu pai?' Eu parava num farol, vinha um cara pedir esmola, ele punha a cabeça para fora e dizia: 'Cadê meu pai?' Perguntava para o porteiro, para a faxineira, qualquer pessoa. E eu tinha sempre a mesma resposta: 'Papai morreu, papai não volta mais' (...), mas não dava conta do que aconteceu. Um dia ele disse: 'Mãe, cadê o papai?'. Eu dizia: 'Mas meu filho, eu já expliquei para você, papai morreu, ele não volta mais'. 'Disso eu já sei, eu quero saber onde que ele está' (...) Aí eu fui à varanda, era um fim de tarde, tinha Vênus nascendo bem luminosa. Eu disse: 'Está vendo aquela estrela bem linda? Papai está lá, papai agora mora lá'. Eu achei que nesse momento ele se aquietou de alguma maneira, pelo menos para essa pergunta (Maria Amélia).

Nas entrevistas 1 e 3 , os parentes permaneceram por certo tempo internados em unidade de terapia intensiva, mas as crianças não foram levadas para visitá-los, pois as mães achavam que já estavam muito comprometidos, e que vê-los nessa situação seria muito penoso para os filhos.

Naquele momento, eu não quis (levar as crianças para visitarem o pai na UTI), que eu achei que ele já estava comprometido demais, ele não responderia. Então eu achava que, para o maior, era muito penoso ver o pai tão comprometido. E eu achava que como ele não tinha esperança nenhuma (...), eu achava uma coisa sem glória. Vou levar ele lá para quê? (Maria Amélia).

Percebe-se que, em alguns casos, tão difícil quanto a própria perda podem ser as deformações e as alterações intensas na aparência que o agravamento da doença e os tratamentos nas UTIs podem provocar. A questão que fica é: levar os filhos para verem o pai no hospital não seria uma forma de preparação para a morte? Seria maior a dor de uma despedida com imagens marcantes ou a dor de não se despedir? Ao levantar essas questões, não se busca uma homogeneização dos processos do luto, e sim, preservar a singularidade, as necessidades do enlutado em cada caso particular.

Nenhuma criança participou do velório, enterro ou cremação. As crianças mais velhas foram consultadas se queriam ou não ir, e, diante da explicação sobre esses ritos, decidiram que não participariam, pois queriam guardar a imagem que tinham de seu ente querido ainda em vida.

(...) Disse para ele se ele queria ir ao enterro. Aí ele me perguntou como é que o pai dele estava. Eu disse: 'Como você já viu em filme, num caixão, cheio de flores, com as pessoas em volta, vela e tal, é assim que ele está'. Ele disse: 'Então eu não quero ir, quero guardar dele a lembrança que eu tenho dele vivo' (Maria Amélia).

A dúvida acerca do que pode acarretar, para uma criança, a participação nos rituais funerários ou uma visita à UTI influenciou na tomada de decisão das mães. Decidiram não levar os filhos por não saberem o que poderia acontecer com eles caso participassem dessas situações. 
Eu achava que ia trazer uma angústia para o meu filho, maior do que eu supunha que a gente pudesse levar avante. (...) Na verdade, eu estava muito confusa, porque eu não sabia se tinha que levar na UTI, se não tinha, mas eu não era a fim de que ele visse aquela imagem porque ele era muito chegado no pai e o pai estava muito feio. Então eu não o levei na UTI para ver (Maria João).

Em uma sociedade que interdita a morte, a participação de crianças em velórios e enterros gera questões, pois existe a crença de que esses eventos poderiam causar sofrimento à criança. Entretanto, Schoen, Burgoyne e Schoen (2004) salientam que os rituais oferecem conforto e suporte, ajudando a elaborar perdas de forma construtiva. O contexto social dos rituais ajuda na aquisição de significados, assim crianças têm a oportunidade de se despedir do falecido, tendo seus sentimentos reconhecidos, acolhidos e compartilhados. Para Schachter (1991-1992), a criança é membro da família, por isso, é importante que participe dos rituais propostos.

A reação imediata da maioria das crianças à comunicação da morte foi de choro, que foi acolhido com um abraço. A longo prazo, a agressividade foi um fator presente no comportamento das crianças. É importante tentar compreender o comportamento agressivo e possibilitar outra válvula de escape para a dor, a raiva e outros sentimentos, convidando a criança a manifestá-los.

(...) Outra reação que ele tinha logo no início, muita agressividade comigo. (...) Eu acho que em casa ele ficou mais agitado, mais briguento. Agora o Fernando está mais calmo (...) Ele agora até cede demais, foi para o outro lado (Maria Rita).

As crianças menores também apresentaram comportamento consumista, não suportando ouvir um não quando seus parentes decidiam não dar o que queriam:
Outra coisa, de alteração de comportamento que teve: na época, ele ficou com uma coisa, assim, de querer comprar coisas. Era uma coisa escancarada, ele entrava em desespero, era uma coisa que ele já tinha um pouco (...) Isso se agravou muito depois da morte da irmã, ele entrava em desespero para comprar uma coisa que ele queria, dava pena dele, e a gente não comprava (...) Aí, foi abrandando, eu me lembro que uma vez eu conversei com ele sobre isso, eu falei: 'Olha, eu sei que dá vontade de comprar um monte de coisas, porque a gente fica querendo ter coisas, por causa da saudade que a gente tem, da falta que a gente sente, mas não é isso, isso não vai resolver o problema. É bom comprar quando a gente quer comprar, precisa, mas não por isso. Não vai resolver'. Enfim, aí foi trabalhando em análise, isso melhorou (Maria Rita).

(...) Nos anos seguintes, o M. fez todos os desafios que ele pôde no mundo. Eu tinha uma ideia de que faltava ali essa marca masculina da autoridade (...) Você dizia um não qualquer, e ele emburrava, ele queria, e aí ele entrava numa espécie de um transe, de um surto, que nem aquelas crianças que se jogam no chão e esperneiam. Ele entrava no quarto dele, ele pegava as cobertas da cama, arrancava, jogava no chão, ficava bravo e desafiava (Maria Amélia).

Segundo duas mães entrevistadas, a experiência de perda ajudou no amadurecimento dos filhos. Essa pode ser uma resposta às expectativas da família, muitas vezes depositadas sobre a criança: ser forte, tomar conta da casa ou dos sobreviventes. Em alguns casos de perda do pai, por exemplo, o filho pode ser incumbido de assumir o lugar de homem da casa.

(...) Ele tem um avô que fala para ele o tempo todo que ele tem que cuidar da mãe, que ele é o homem da casa (...) (Maria João).

Percebe-se o quanto a morte pode alterar os modos de existir. Nadeau (1977), citada por Franco (2010), retoma essa questão do significado no interior do grupo familiar. Novos significados trazem outras facetas à identidade já existente: filhos viram órfãos, casados 
viram viúvos/as, com novas configurações nas várias organizações familiares e sociais. Para Fukumitsu (2004), a possibilidade de lidar e enfrentar a morte é a possibilidade de ressignificação que essas situações permitem; pode-se ver aqui como age a função dual do processo de luto, que é lidar com a perda e buscar a reorganização da vida em família.

O sentimento de culpa apareceu nas quatro entrevistas, tanto nos adultos quanto nas crianças. Principalmente nas crianças, a culpa é estimulada pelo pensamento egocêntrico e animista, característico do nível préoperacional do desenvolvimento, sendo, muitas vezes, o produto de sentimentos ambivalentes (Torres, 1999). A rivalidade, comum entre irmãos, é outro elemento que frequentemente contribui para uma intensa culpa no sobrevivente, sendo, portanto, fundamental esclarecer que o eventual desejo de destruição ou de morte do irmão não foi a causa da morte (Lione 2005), situação que pode ser observada neste diálogo entre Maria Rita e Fernando:

No início, tinha muito uma coisa assim, de culpa, ele falava: 'Mãe, eu brigava tanto com a minha irmã, não é?' Eu falava: 'Não, é porque irmão briga, mesmo'. Aí ele falava: 'Mas eu a chamava de idiota'. Aí eu falei: 'Ela também te chamava' (Maria Rita).

Outras fantasias, como, por exemplo, a volta do ente querido morto, apareceram explícita ou implicitamente nas crianças. Uma delas se recusava a sair de casa para ir a qualquer lugar, como se estivesse à espera do pai; outra disse que iria buscar a irmã no céu:

Nos dois primeiros meses, talvez mais no primeiro mês, ele ficava assim: 'Mãe, eu vou com a minha espada, com a minha corda de homem aranha, vou jogar no céu e vou buscar a minha irmã para a gente'. E a gente falava que essa coisa de ficar no céu é uma forma da gente falar, mas que não dava para buscar, trazer do céu para cá de volta (Maria Rita).
Essas observações corroboram dados da literatura que apontam a dificuldade das crianças mais novas em compreender a irreversibilidade da morte (Torres, 1999).

Crianças muito pequenas apresentaram dificuldades para lembrar seus parentes mortos. Na tentativa de auxiliá-las a formar e conservar imagens do ente perdido, alguns adultos mostraram fotos, trazendo à tona diversas recordações. Fotos e narrativas são uma das formas de se preservar memórias, mantendo os laços contínuos, como apontam Klass, Silverman e Nickman (1996).

\begin{abstract}
(...) Uma das coisas que ele também me disse a certa altura (...) é que ele lembrava pouco do pai. Ele disse: 'Eu não me lembro. Eu lembro de três cenas: meu pai parado na porta, meu pai ficando bravo comigo porque eu fui mexer nos discos dele e do meu pai me dando macarrão na boca do prato dele, que ele estava comendo'. Então tinha aí um pedido também de falar desse pai, e isso eu fiz. (...) Eu fui buscar uma porção de fotos em que o pai estava carregando ele no colo, procurei as mais alegres e felizes e fui mostrando, colei do lado do berço para ele. (...) Eu fui o tempo inteiro montando essa imagem, porque eu achei que eles eram muito pequenos (...). Eu me achei no lugar de ajudá-los a construir uma boa imagem, nem que ela não fosse inteira, porque certamente a imagem, ainda mais construída pelo outro, não é a imagem que você constrói do seu pai (Maria Amélia).
\end{abstract}

Já as crianças mais velhas se lembravam de seus entes queridos frequentemente e com riqueza de detalhes. Entretanto, a capacidade de lembrar e de falar do parente querido que se foi não pareceu estar ligada apenas à idade da criança à época da perda, mas também à disponibilidade da família para acolher essas comunicações (Lima, 2007).

De acordo com Silverman e Worden (1999), não é necessário esquecer os mortos para continuar vivendo. Lembrar-se do genitor falecido, encontrar um lugar novo para ele na existência da criança ajuda a estabelecer 
paz e harmonia com o passado. Harris afirma que crianças podem manter a continuidade do vínculo com o familiar morto de modo mais explícito do que adultos.

Meninos que perderam os pais acabaram por adquirir comportamentos parecidos com os deles, reproduzindo seus traços mais marcantes de personalidade. Alguns assumiram o papel de homem da casa, um deles pediu a mãe em casamento, outro passou a tomar conta dela.

(...) Ele é igual ao pai dele, aquele que todo mundo gosta, que faz o maior sucesso, sabe? Cheio de amigos (Maria João).

A reação dele foi de cuidar de mim. Ele não me deixava vê-lo chorar. Foi uma coisa assim de não me deixar sofrer, então ele ficou durão por um bom tempo, inclusive (Maria João).

A prática de trazer a criança enlutada para dormir com o adulto responsável, também enlutado, foi comum entre os entrevistados, que reconheceram não saber se foi uma necessidade da criança ou deles. Talvez ambos necessitassem dessa proximidade.

Ele dormiu comigo, na minha cama, por quase um ano, e eu, na verdade, até hoje eu não sei se ele dormia na minha cama porque ele precisava ou porque eu precisava. Eu sei que ele se enfiava lá na minha cama, dormia lá comigo (Maria João).

A questão das datas comemorativas também apareceu no relato da maioria dos entrevistados: Maria Amélia torcia para que a família ainda pudesse passar reunida as festas de fim de ano. Para Maria João, além das festas de fim de ano, também foi muito difícil o primeiro Dia dos Pais. Maria Rita trouxe como um momento doloroso a festa junina da escola, evento muito apreciado pela filha falecida. Essas datas trazem à tona novamente os sentimentos relacionados à perda, configurando as reações de aniversário apontadas por Cassorla (1991).

Dia dos Pais é uma droga, porque na escola fazem presente para os pais. E eu conversei lá na orientação, e elas disseram que não iam forçar, que iam deixar ele bem à vontade para decidir se queria ou não participar. Não sei se elas falaram isso para mim e depois induziram, mas eu sei que ele sempre fez. A professora dele ano passado era uma amiga minha, ela disse que ele queria, ele topava fazer e que ela falava: 'Dá para alguém que você gosta'. Mas ele nunca deu para ninguém (Maria João).

O apoio da família extensa na situação de perda foi muito importante tanto para a criança quanto para o responsável. Já no dia do ocorrido, parentes acolheram as crianças em suas casas, enquanto seus responsáveis tomavam providências e iam ao velório e ao enterro. Essa solidariedade continuou por longo tempo durante o processo de luto da criança e de seu responsável, o que parece ter influenciado positivamente na sua elaboração.

(...) O meu filho tem um monte de primo, a gente catou todo mundo, estava todo mundo na casa; a casa da minha mãe parecia um clube de férias. Todo mundo lá. Então eu tenho a impressão que isso deu uma segurada nele (Maria João).

Acho que o meu contexto familiar é um contexto muito acolhedor, tenho uma família muito unida. Eu tinha dois irmãos, tinha minha mãe ainda viva. Então eu tive muito suporte familiar (Maria Amélia).

Em todas as entrevistas, ficou claro que ter uma criança para cuidar foi um fator decisivo na reestruturação emocional dos responsáveis. A criança, ao presenciar a dor do adulto, expressava reconhecimento e acolhimento. O cuidado entre criança e responsável enlutados mostrou-se uma via de mão dupla, apesar de os responsáveis, em sua maioria, terem escondido das crianças o seu pesar. 
(...) Me foi útil essa coisa de ficar muito de pé e cuidar muito das crianças. E, por outro lado, também as crianças te impõem na vida, você tem aí uma via de duas mãos, porque, se por um lado eu me apurava para estar bem para as crianças, para fazer elas ficarem de pé, por outro lado, foram eles que me deram todo esse gás. (...) Muitas vezes, quando eu ficava com os olhos cheios d'água, meu maior dizia: 'Chora, mãe, chora, pode chorar, nós estamos aqui'. Eles foram muito amparadores também (Maria Amélia).

Eu fiquei deprimida, eu fiquei muito deprimida. Foi mesmo o meu neto que me ajudou a levantar (Maria Eduarda).

A terapia foi um recurso buscado por quase todos os participantes, diante da experiência devastadora que foi a perda da pessoa amada. Maria Amélia e Maria João buscaram atendimento psicológico para si próprias. Fernando esteve em análise inicialmente por motivo diverso da perda, permanecendo até a data de realização da entrevista. Cabe ressaltar que a terapia não é sempre necessária em casos de perda por morte, visto que o luto não é doença, mas pode contribuir muito como auxiliar no processo de reconhecimento e de elaboração dos sentimentos vinculados à perda, tanto para a criança quanto para o adulto (Kovács, 1992).

\section{Considerações finais}

Nota-se o quão difícil é comunicar à criança a morte de uma pessoa amada. Os dados deste trabalho mostram que algumas famílias conseguem fazê-lo de forma mais natural e favorável à elaboração do luto na criança. Outras famílias, padecendo de um sofrimento intenso, paralisadas pela própria dor, podem ter maiores dificuldades para oferecer toda a disponibilidade que uma criança demanda. É diante dessa fragilidade no núcleo familiar que se coloca a necessidade do apoio da família extensa, dos amigos, da comunidade e de profissionais.
De modo geral, as crianças parecem ter respondido ao modelo passado por seus responsáveis: quando o silêncio em torno da morte foi quase total, a criança, talvez pela pouca idade, acabou esquecendo a pessoa morta. Quando a dor da mãe foi muito intensa e explícita, a criança passou a cuidar dela escondendo o próprio pesar para não causar sofrimento adicional. Nas situações em que se conversou abertamente e com frequência sobre o ente perdido, as crianças pareceram mais à vontade para mostrar seus sentimentos e fazer perguntas.

Dessa forma, algumas tarefas importantes a serem desempenhadas por aqueles que têm sob seus cuidados uma criança enlutada são (Torres, 1999):

\section{- ser bom ouvinte;}

- promover uma comunicação aberta e adequada aos níveis de compreensão da criança;

- permanecer atento às comunicações verbais e não verbais da criança;

deixar que ela dê o tom e estabeleça o ritmo da conversa;

- promover a participação das crianças nos rituais, com consentimento e informação;

- trabalhar as fantasias da criança com relação à morte, principalmente as de culpa e as de um possível retorno da pessoa morta;

- possibilitar a expressão não só da tristeza mas também de sentimentos como raiva, desamparo e medo;

- ajudar as crianças a formar e a manter uma imagem de seu ente querido, por meio da recordação de experiências vividas, facilitada pelo uso de narrativas, fotos, filmes, etc.;

- buscar apoio de toda a rede de relacionamento social, de cada membro da família, dos amigos, vizinhos, professores, profissionais e de todos os que puderem dar sua contribuição para o sucesso final.

Nesse contexto, a escola ocupa lugar de destaque, sendo fundamental que abra 
espaço para o tema da morte, tratando-o de maneira natural e sensível. Propõe-se, à direção das escolas, que sensibilizem e instrumentalizem os educadores para essa prática, oferecendo não só conhecimentos sobre desenvolvimento infantil e processo de luto mas também espaços para reflexão sobre nossos limites e medos frente ao tema da morte (Kovács, 2010).

Essa proposta se estende a toda a sociedade, conclamando uma mudança mais ampla que somente se dará quando vislumbrarmos novas formas de nos relacionarmos com a finitude humana. Tratar da morte, tema tabu, com mais naturalidade requer uma revisão abrangente de valores tradicionais e também contemporâneos, como o consumismo desenfreado e o culto à juventude, tão exacerbados em nossos dias. Considerar a morte como possibilidade pessoal é tarefa do ser humano que se inicia já na infância.

\section{Vanessa Rodrigues de Lima}

Mestre Universidade de São Paulo, SP - Brasil.

E-mail: vanessa.lii@ig.com.br

\section{Maria Julia Kovács}

Professora livre docente do Instituto de Psicologia da Universidade de São Paulo, doutorado em Psicologia Escolar e do Desenvolvimento Humano pela Universidade de São Paulo, São Paulo - SP - Brasil.

E-mail: mjkoarag@usp.br

\section{Endereço para envio de correspondência:}

Rua Cinco de Julho, 111 apto. 202. Copacabana, Rio de Janeiro - RJ - Brasil CEP 22051-030 
Referências
Anthony, S. (1972). The discovery of death in childhood and after. New York: Basic Books.

Ariès, P. (1977). História da morte no ocidente: da idade média aos nossos dias. Rio de Janeiro: Francisco Alves.

Bowlby, J. (1982). Formação e rompimento dos laços afetivos. São Paulo: Martins Fontes.

Bromberg, M. H. P. F. (2000). A psicoterapia em situações de perdas e luto. Campinas, SP: Livro Pleno.

Cassorla, R. M. S. (1991). Do suicídio. Estudos brasileiros. Campinas, SP: Papirus.

Franco, M. H. P. (2002). Uma mudança no paradigma sobre o enfoque da morte e do luto na contemporaneidade. In M. H. P. Franco (Org.), Estudos avançados sobre o luto. Campinas, SP: Livro Pleno.

Franco, M. H. P. (2010). (Org.), Formação e rompimento de vínculos: o dilema das perdas na atualidade. São Paulo: Summus.

Freud, S. (1974). Luto e melancolia . In Edição standard brasileira das obras completas de Sigmund Freud, (Riviere, Joan, trad., Vol. 14, pp. 275-292). Rio de Janeiro: Imago. (Trabalho original publicado em 1917)

Fukumitsu, K. O. (2004). Uma visão fenomenológica do luto: um estudo sobre as perdas no desenvolvimento humano. Campinas, SP: Livro Pleno.

Harris, E. S. (1991). Adolescent bereavement following the death of a parent. An exploratory study. Child Psychology and Human Development, 21(4), p. 17-32.

Harris, M. (1995). The loss that is forever: The lifelong impact of early death of a mother or a father. New York: Dutton Book.

Kastenbaum R., \& Aisenberg R. (1983). Psicologia da morte. São Paulo: Pioneira: Ed. da Universidade de São Paulo.

Klass D., Silverman P., \& Nickman, S. (1996). Continuing bonds. New understandings of grief. Nova York: Taylor e Francis.

Kovács, M. J. (1992). Morte no processo do desenvolvimento humano. A criança e o adolescente diante da morte. In J. M. Kovács, Morte e desenvolvimento humano (pp. 49-58). São Paulo: Casa do Psicólogo.

Kovács, M. J. (2003). Educação para a morte: temas e reflexões. São Paulo: Casa do Psicólogo.

Kovács M. J. (2010). A morte no contexto escolar. Desafio na formação de educadores. In M. H. P. Franco (Org.), Formação e rompimento de vínculos: o dilema das perdas na atualidade (pp. 145-168). São Paulo: Summus.

Lima, V. R. (2007). Morte na família: um estudo exploratório acerta da comunicação à criança. Dissertação de mestrado. Programa de Psicologia Escolar e Desenvolvimento Humano, Instituto de Psicologia, Universidade de São Paulo, São Paulo.

Lione, F. R. (2005). Sobre as vivências dos irmãos da criança com câncer. In E. Perina, \& N. A. G. Nucci (Orgs.), As dimensões do cuidar em psiconcologia pediátrica. Campinas, SP: Livro Pleno.

Minayo, M. C. S. (2000). O desafio do conhecimento: pesquisa qualitativa em saúde. São Paulo: Hucitec
Neimeyer R. A. (2001). Meaning reconstruction and the experience of loss. Washington, DC: American Psychological Association.

Parkes, C. M., Laugani P., \& Young, B. (1997). Death and bereavement among cultures. Londres: Routledge.

Schachter, S. (1991/1992). Adolescent experience with the death of a peer. Omega, Journal of Death and Dying, 24(1), p. 1-11.

Schoen, A. A., Burgoyne, M., \& Schoen, S. F. (2004). Are the developmental needs of children in America adequately addressed during the grief process? J. Instr. Psychol, 31(2), 143-148.

Silverman, P. R., \& Worden, J. W. (1999). Children's reaction to death of a parent. In W. Stroebe, M. S. Stroebe, \& R. O. Hansson (Eds.), Handbook of bereavement: Theory, research and intervention. Cambridge: Cambridge University Press.

Stroebe, M., \& Schut, H. (2001). Meaning making in the dual process model of coping with bereavement. In R. A. Neimeyer (Ed.), Meaning reconstruction and the experience of loss. Washington, DC: American Psychological Association.

Torres, W. C. (1978). O conceito de morte em diferentes níveis de desenvolvimento cognitivo: uma abordagem preliminar. Dissertação de mestrado da Fundação Getúlio Vargas, Rio de Janeiro.

Torres, W. da C. (1999). A criança diante da morte: desafios. São Paulo: Casa do Psicólogo.Walsh, F., \& McGoldrick, M. (1998). Morte na família: sobrevivendo às perdas. Porto Alegre: Artmed.

Weller, E. B., \& Weller, R. A. (1992). Luto em crianças e adolescentes. Porto Alegre: Artes Médicas. 